STUDII

\title{
COLONII ȘI ARENDA PĂMÂNTULUI ÎN ROMA
}

\author{
ANTICĂ
}

DOI 10.24193/SUBBiur.65(2020).4.14

Data publicării online:

16.03 .2021

\section{Marilena MARIN*}

Rezumat: În această lucrare vom analiza situația legală a colonilor, oameni semi-liberi, agricultori, în perioada Romei antice, precum și particularitățile contractului de arendă a colonului, în aceeaşi perioadă. Am analizat, pentru început, statutul colonistului în contextul societății romane, alături de o scurtă caracterizare a acestora pentru o mai bună înțelegere a motivelor stabilirii unui anumit tip de relație a acestora cu terenurile și stăpânnii lor. Am avut apoi în vedere sursele contractelor de arendare precum și modul în care acestea au influențat efectele acestui contract, în particular, drepturile și obligațiile colonilor. Scopul materialului a fost acela de a genera o prezentare de ansamblu a relației dintre oamenii și pământurile acestora în perioada Romei antice. În același timp, analiza a fost direcționată spre un studiu aprofundat a relației pe care se fundamenta contractul de arendă, pornind de la perspectiva marelui Profesor Vladimir Hanga, care a expus ideea conform căreia: „fiecare legislație este legată de societatea a cărei emanație este.”

Cuvinte cheie: coloni, arendă, sclavi.

* Conf. univ. dr., Facultatea de Drept și Ştiințe Administrative, Universitatea Ovidius, Constanța, marilenamarin@yahoo.com. 


\title{
COLONISTS (SEMI-FREE PEOPLE) AND LAND LEASE IN ANCIENT ROME
}

\begin{abstract}
The present paper analyzes the legal situation of the colonists semi-free people, land cultivators, in the period of ancient Rome, as well as the particularities that the land lease has experienced in relation to the colonist, in the same period of antiquity. We have had as starting point the status of the colonist within the framework of the Roman society along with a brief characterization of them in order to properly understand the reasons for establishing a particular type of relation with the lands and the corresponding owners of them. Hereinafter, we have considered the sources of the lease agreement as well as the outcome/impact of the contract, in particular the rights and obligations of the settlers.

The topic that might be labelled as out of interest has been intended to create a general overview in respect of the people and their relationship with the lands in general with focus on the period of ancient Rome. At the same time, the analysis has been directed towards an in-depth study as regards the legal relationship on which the lease contract was based, starting from the perspective of the great professor Vladimir Hanga, who expressed the idea according to which "Every legislation is related to the society from which it comes and on which it depends".

The research method in point of the text has been the observation and analysis of documents, the exact identification of the tackled concepts in respect of time and space, but also an accurate understanding of the legal situation of the colonists - semi-free people who worked the land during ancient Rome.
\end{abstract}

Keywords: semi-free people, colonist, colonial/settlers, lease agreement, slavery relationships, tenant, tenancy. 


\section{Cuprins}

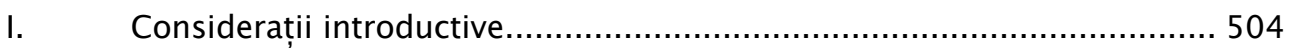

II. Status hominis, categorii de persoane în societatea antică romană. Colonii 505

III. Contractul de colonat în dreptul roman ........................................... 509

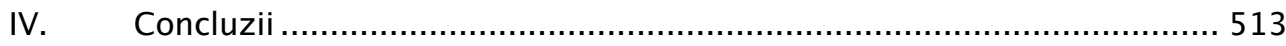

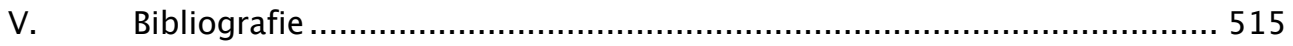

\section{Considerații introductive}

Colonatul, care era corespondentul contractului de arendă din zilele noastre, a apărut în perioada societății sclavagiste romane, aflată într-o perioadă de declin, dar și ca efect al descompunerii relațiilor sociale de tip sclavagist, prevestind trecerea la sistemul de tip feudal. Instituția colonatului a fost o măsură juridică cu caracter revoluționar prin care, la început, se realiza un raport juridic între două persoane din categoria oamenilor liberi, dar care, cu timpul, se va schimba, colonul pierzându-şi libertatea, fiind legat de glie, de pământul pe care îl muncea.

Apariția colonatului a fost posibilă ca urmare a existenței următorilor factori: extinderea proprietăților funciare în detrimentul micilor proprietăți, care erau absorbite de adevărate latifundii; pe fondul necesității micilor proprietari de a asigura subzistența familiei și în favoarea celor învinși în campaniile militare purtate împotriva Romei, colonatul fiind privit ca o formă de optimizare a exploatării agricole ${ }^{1}$.

${ }^{1}$ V. M. Ciucă, Drept roman. Lecțiuni, ed. a II-a, addenda, corrigenda et incrementa, Editura Universităţii „Alexandru Ioan Cuza”, Iași, 2014, p. 266. 
Potrivit opiniei prof. Vladimir Hanga, în sec. I d.Hr, noțiunea de „colonat” s-a extins în întreaga societate romană, care era o societate de tip sclavagist. Izvoarele vremii (lucrări de agronomie contemporane cu acea perioadă) au scos în evidență superioritatea exploatării moșiilor pe calea arendării acestora, pe parcele, unor mici cultivatori denumiți „coloni””

Terminologia utilizată în cuprinsul acestei lucrări nu are în vedere și analiza noțiunilor de colonizare, rezultată din cantonarea unor trupe de către Imperiul roman în provinciile nou cucerite, după cum nu ne vom referi nici la subdiviziunea administrativă a statului roman denumită coloniae (persoană juridică de drept public) $)^{3}$.

\section{Status hominis, categorii de persoane în societatea antică romană. Colonii}

Societatea antică romană și dreptul privat roman nu recunoșteau tuturor indivizilor cele trei condiții esențiale ale capacității juridice (status libertatis, status civitatis și status familiae), mai ales că, pentru anumite categorii de persoane, aceste condiții trebuiau să fie îndeplinite cumulativ pentru a putea produce efecte juridice (exmplu: categoria cetățenilor romani).

După clasificarea făcută de Gaius cu privire la oameni în perioada Romei antice, aceștia se împărțeau în oameni liberi și sclavi. Dacă la început dreptul roman identifica status libertatis cu cetățenia și recunoștea calitatea

\footnotetext{
2 Vl. Hanga, M. Jakotă, Drept privat roman, Editura Didactică și Pedagogică, București, 1964, p. 118; V. M. Ciucă, op. cit., p. 266.

3 T. Sâmbrian, Drept Roman. Principii, instituții și texte celebre, Casa de editură și presă „Șansa” S.R.L., București, 1994, p. 110.
} 
de om liber doar cetățenilor Romei, cu timpul, romanii au recunoscut statusul de om liber şi altor persoane decât cetățenilor romani.

Condiția juridică recunoscută de Roma antică oamenilor liberi nu era uniformă. Aceștia erau împărțiţi în patru categorii, după cum urmează ${ }^{4}$ : ingenui, fiind acei oameni liberi care s-au născut din părinți liberi ori care sau născut din părinți dezrobiți; aceștia, la rândul lor, puteau fi cetățeni (sau latini - latinii vechi, latinii din colonii, latinii iuniani sau latinii fictivi; asimilaţi latinilor coloniari) şi necetățeni (sau peregrini - peregrinii obişnuiţi sau peregrinii dediticii); liberții sau aşa-numiții oameni liberi care au fost înainte sclavi; în această categorie puteau intra atît cetățeni ai Romei, cât și necetățeni; oameni liberi cu o condiție specială, în categoria cărora intrau persoanele aflate in mancipio (ca efect al vânzării lor ca scalvi sau ca efect al abandonului noxal); oamenii liberi care slujeau unui alt om liber dintr-o eroare comună; persoanele addicti (debitori insolvabili care erau atribuiți creditorilor lor); auctorati (oamenii liberi care se angajau ca gladiatori); redempti ab hostibus (persoanele răscumpărate de la duşman); colonii (colonus; colere) erau cultivatori de pământ și aveau statut de oameni semiliberi).

Din punctul de vedere al statutului lor juridic, colonii erau oameni folosiți la cultivarea terenurilor părăsite. Ulterior, începând cu jumătatea sec. I d. Hr., colonii au devenit oameni liberi care lucrau terenul unui proprietar întocmai ca un arendaş, în temeiul unui contract denumit colonat (contract de arendă - locatio conductio $)^{5}$. Tot colonat se numea şi arenda pe care colonii se obligau să o plătească.

\section{Idem, p. 59.}

5 Vl. Hanga, M.D. Bocşan, Curs de drept privat roman, ed. a II-a, Editura Universul Juridic, București, 2006, p. 124.

\section{6}


Modul în care romanii priveau munca salariată era diferit, în funcție de categoria socială căreia îi aparțineau. Izvoarele istorice atestă disprețul manifestat de către majoritate membrilor elitei față de acest tip de muncă. Armata reprezenta o excepție, întrucât soldații, odată cu lăsarea la vatră, primeau un suport care le permitea să ducă un trai decent. Uneori, aceștia ajungeau să lucreze în cadrul unor mici ferme. ${ }^{6}$

Odată cu evoluția societății romane, statutul juridic al colonilor se modifică. Din cauza poverii muncii pe care trebuiau să o îndeplinească, colonii au început să fugă de pe moșii, abandonându-le. Prin urmare, dacă până în sec. al III-lea d. Hr colonii beneficiau de libertate deplină de regulă, în cea dea doua parte a perioadei imperiului (perioada dominatului), mai exact, în timpul Împărtului Constantin, a fost emis un edict imperial prin care colonii liberi au fost legați de glie, devenind astfel servi terrae (sclavi ai pământului sau coloni servi). Situația juridică a colonilor era aceea de oameni liberi, dar în fapt, acesția aveau o situație asemănătoare sclavilor. Abia în sec. al IV-lea d. Hr. ordinea juridică romană va sancționa acest procedeu al legării de glie al colonilor.

Această formă a legării de glie se va regăsi ulterior şi în perioada medievală, mai exact, în perioada feudalismului timpuriu, când apare noțiunea de şerbie.

Dreptul roman recunoştea colonilor calitatea/statusul de persoană, subiect individual, om liber, cu aptitudinea de a avea drepturi şi de a-şi asuma obligații. În această calitate, un colon beneficia de drepturi, cum ar fi: dreptul de a se căsători și de a avea copii care, la rândul lor, erau oameni liberi; dreptul de a exercita puterea părintească asupra copiilor săi; putea deține bunuri în

\footnotetext{
${ }^{6}$ Mary Beard, SPQR. O istorie a Romei antice, Editura Trei, București, 2017, p. 393.
}

\section{$\mathbf{5 0 7}$}


proprietate (și chiar i se recunoște dreptul de proprietate asupra parcelei de pământ pe care a pus-o în valoare prin muncă proprie) și putea dispune de bunurile sale prin testament, precum și prin diferite acte juridice, cu condiția ca, la încheierea actelor respective, să primească și acordul stăpânului la înstrăinare. Prin această condiție impusă colonului în dreptul roman se poate considera că patrimoniul acestuia și condiția sa juridică sunt asemănătoare sclavilor și patrimoniului acestora (denumit peculium). Colonul datora taxe și impozite intuituu personae pentru folosinţa terenului.

Totodată, colonilor li se aplicau și alte restricții, limitări ale lui status libertatis, care îi apropiau de situația juridică a unui sclav, respectiv: un colon nu putea părăsi domeniul pe care lucra (până la achitarea integrală a datoriilor ${ }^{7}$ ), iar la înstrăinarea terenului asupra căruia colonul exercita arenda, era vândut și colonul, care era privit ca un accesoriu al terenului; proprietarul terenului (devenit, între timp, stăpânul său) putea exercita un drept de corecție asupra colonului; colonul nu îl putea chema în judecată pe stăpânul său decât în cazuri excepționale; un colon nu se putea căsători cu o femeie liberă, ci doar cu o femeie care avea aceeași condiție juridică cu a sa ${ }^{8}$.

Potrivit izvoarelor vremii, principlalele restricții care erau impuse colonilor, priveau condițiile în care aceștia puteau denunța contractul de colonat, în raport și de situația financiară a Imperiului, respectiv, perioada de inflație cu care acesta se confrunta la începutul sec. al IV-lea. În acest context, Împăratul Dioclețian a promulgat Edictum de pretiis venalium rerum, prin care stabilea valori maxime pentru o bună parte dintre bunurile care se

7 V. M. Ciucă, p. 268.

${ }^{8}$ Vl. Hanga, M.D. Bocşan, p. 124. 
tranzacționau în acea perioadă și, ca sancțiune pentru nerespectarea acestor valori, a stabilit pedeapsa capitală.

\section{Contractul de colonat în dreptul roman}

Contractul de colonat era definit ca fiind o varietate a contractului de locaţiune (locatio conductio) în dreptul roman. Pornind de la contractul de locațiune, reținem că acesta era definit ca fiind convenția prin care o persoană (denumită locator) se obliga să îi procure altei persoane (denumită conductor) folosința temporară a unui lucru sau serviciile sale ori să îi execute o anumită lucrare în schimbul unei sume de bani numită merces 9 .

Izvoarele contractului de colonat erau următoarele ${ }^{10}$ : nașterea (asemenea cazului celorlalte categorii sociale, de regulă, colonii transmiteau această calitate/stare copiilor lor, fiind suficient ca doar unul dintre părinți să fie colon); prescripția achizitivă (în materia colonatului, doar prescripția achizitivă de 30 de ani putea produce efecte în privința colonatului, ca sursă/izvor; potrivit acestei instituții, persoana care fusese colon timp de 30 de ani rămânea colon pe viață; această regulă a fost desființată în vremea Împăratului Iustinian); convenția (reprezenta acel izvor al colonatului prin care omul liber se vindea ca şi colon proprietarului de pământ, iar documentul care conţinea convenția era păstrat în arhivele cetăţii - municipalia gesta); prizonieratul (persoanele care cădeau în prizonierat nu puteau dispune de libertatea lor, astfel încât ele erau atribuite marilor proprietari de pământ de către statul roman, mai ales că numărul sclavilor nu acoperea și activitatea de

9 T. Sâmbrian, op.cit., p. 155

${ }^{10}$ Idem, p. 66 
cultivare a terenurilor); pedeapsa (colonatul putea avea ca izvor și sancțiunea, când, persoanele apte de muncă ce erau descoperite de către stăpânul pământului că practicau cerșetoria, vagabondajul sau alte asemenea fapte, erau transformați în coloni).

În raport de obiectul contractului sau al locației, aceasta se clasifica în locatio rei (locațiunea unui bun, pe care îl putem asimila contractului de locaţiune din zilele noastre, în dreptul românesc), locatio operarum (locațiunea unui serviciu, ce poate fi asimilat contractului de muncă din dreptul românesc actual) și locatio operis facendi (locațiunea pentru executarea unei lucrări, care poate fi asimilat contractului de antrepriză din dreptul românesc actual).

În ceea ce privește studiul nostru, ne interesează analiza contractului locatio rei, care reprezenta închirierea unui bun corporal mobil sau imobil.

Sub aspectul părților contractante și al obiectului contractului, acesta putea fi încheiat între chiriaş/locator și proprietarul terenului, direct ori prin reprezentarea acestui proprietar şi trebuia să fie validat de către autoritățile statului roman. Persoanele împuternicite de către proprietari erau fermierii generali, cunoscuți sub denumirea de conductores. Când bunul care făcea obiectul locației era un bun imobil - clădire, locatorul se numea inquilinus; dacă bunul ce făcea obiectul contractului era un teren (fond rustic), locatorul se numea colon (colonus). La început, contraprestația pentru folosința terenului de către arenda/colonatul se datora în bani, pentru ca mai târziu, ca urmare a sărăcirii colonilor, aceștia să plătească în natură colonatul.

Primele persoane cunoscute în Roma antică, ce aveau calitatea de arendaşi în contractul de colonat, au fost colonii voluntar $i^{11}$. Dintre aceștia, o

${ }^{11}$ Idem, pp. 65-66. 
categorie aparte o reprezentau colonii parțiari/parțieri, cei care se obligau la plata colonatului în produse, ocazie cu care remiteau o parte a recoltei adunate de pe terenul arendat. Cealaltă categorie de coloni voluntari erau denumiți coloni simpli, care achitau colonatul (arenda/chiria) fie în bani, fie în natură, prin executarea unor lucrări în favoarea proprietarului pământului.

O altă categorie de coloni erau colonii involuntari/siliți, apăruți la finele sec. III d. Hr. Aceștia erau prizonieri de război care nu mai erau transformați în sclavi, ci repartizați marilor proprietari pentru a lucra pământul şi erau considerați coloni ${ }^{12}$. În timpul Împăratului Marc Aureliu, prizonierii de război nu mai erau transformați în întrgime în sclavi, ci, în mare parte, erau atribuiți marilor latifundiari, pentru a le fi lucrate pământurile. Și astfel, în timp, colonatul va ajunge să se substituie sclaviei ${ }^{13}$, cu atât mai mult cu cât munca sclavilor devenise tot mai neproductivă în sec. I d. Hr.

Dreptul roman a cunoscut și o a treia categorie de coloni, denumiți coloni adscripticii (coloni adăugați sau supranumerari ai micilor proprietari de terenuri). În această categorie de coloni erau incluşi aceia care nu mai puteau trăi din lucrul propriilor terenuri și au acceptat să devină coloni. Colonii adscripticii au apărut ca efect a unei novella dată de Împăratul Valentianianus, iar ulterior a fost confirmată de către Împăratul Justinian.

Părțile contractante puteau stabili durata contractului, de comun acord. Contratul de colonat/arendă putea fi încheiat pe termen maxim de cinci ani, colonii putând alege între posibilitatea renunțării la contract ori a reînnoirii acestuia. În timpul Împăratului Justinian a fost reglementată noțiunea tacita reconductio (corespunzătoare noțiunii actuale de tacită

12 E. Molcuț, D. Oancea, Drept roman, Casa de editură și presă „Şansa” SRL, Editura Universul, București, 1993, p. 94.

13 Vl. Hanga, M.D. Bocşan, op. cit., p. 122. 
relocațiune din dreptul românesc) care permitea prelungirea tacită a contractului, cu condiția ca cel care avea calitatea de chiriaş/colon continua să lucreze terenul, fără ca proprietarul acestuia să se opună. De asemenea, dacă vreuna dintre părți deceda, pe durata contractului de colonat, succesorii celui decedat se puteau subroga în drepturile și obligațiile autorului lor.

Pentru contractul de colonat, ca, de altfel, pentru toate tipurile de contracte de locațiune, romanii au stabilit acțiunile care puteau fi formulate în justiție, în caz de nerespectare a clauzelor contractuale sau ale dispozițiilor legale care guvernau acest tip de contract. Cele două acțiuni care sancţionau drepturile izvorâte din contractul de colonat erau: actio ex locato/actio locati (de care dispunea proprietarul bunului) și actio ex conducto/actio conducti (aflată la dispoziția colonului). Ambele acțiuni tindeau la executarea corectă și completă a obligațiilor asumate de către părți prin intermediul contractului încheiat, fiind acţiuni directe și de bună-credință.

În situația în care un proprietar de pământ intenționa să vândă terenul, acesta trebuia să îl includă în obiectul vânzării și pe colonul care lucra acel pământ, nefiind posibilă vânzarea separată a fondului şi a colonului. O asemenea vânzare era sancționată cu nulitatea actului. Totodată, legea romană interzicea proprietarului de terenuri sa îşi mute colonii de pe o parcelă pe alta, indiferent de motivul mutării.

Încetarea sau stingerea colonatului avea loc în foarte puține cazuri, potrivit regulilor dreptului roman, respectiv: prin renunțarea proprietarului, în același timp, atât la terenul al cărui proprietar era, cât şi la colonul care cultiva terenul respectiv, iar renunțarea urma a se face în favoarea colonului; când se împlineau, cumulativ, următoarele condiții: exista acordul proprietarului şi colonul dobândea rang clerical sau mânăstiresc; la împlinirea prescripției de 30 de ani, pentru bărbați, și de 20 de ani, pentru 
femei, prevedere care se desființează în timpul Împăratului Justinian; când colonul intra în armata romană, dacă interesele statului impuneau măsura înrolării acestuia.

Deşi ar fi putut să înceteze şi la împlinirea termenului pentru care s-a încheiat contractul respectiv (de regulă, după perioada maximă de cinci ani), despre această posibilitate de încetare a contractului de colonat dreptul roman „tace”.

\section{Concluzii}

Analizând noțiunile de colon și de contract de colonat din perspectivă istorică, juridică, politică şi economică, am constatat, o dată în plus, că statul roman, de-a lungul existenței sale, a creat pârghii prin intermediul cărora a asigurat muncile agricole, în condițiile în care granițele se extindeau, înglobau noi teritorii, numărul sclavilor era insuficient, în scădere, iar numărul prizonierilor de război creștea. Ordinea juridică romană s-a adaptat continuu, ea inseși a evoluat în raport cu evoluția societății, stabilind reguli stricte care să îi permită satisfacerea aristocrației romane, chiar dacă această satisfacție se răsfrângea în mod negativ asupra altor categorii sociale.

În acest context, întâlnim colonul, de cele mai multe ori, țăran liber la origine, care ajunge sub povara datoriilor ori strâmtorat de nevoi, care alege să lase pământul în grija unui protector care îi garantează că va interveni în favoarea sa în faţa creditorilor sau a autorităţilor adminsitrative ori judecătorești. Regăsim această imagine atât în perioada Republici romane, cât şi mai apoi, în etapa Imperiului şi, mai târziu, în epoca medievală întrucât istoria a oferit o anumită ciclicitate: instituțiile apărute în zorii istoriei se 
regăsesc în epocile următoare, cu anumite caracteristici specifice nivelului de dezvoltare a societății.

$\mathrm{Cu}$ atât mai mult cu cât vorbim despre măreția dreptului roman, care reprezintă fundamentul juridic actual al legislației multor popoare, şi baza unuia dintre cele două mari sisteme de drept care guvernează lumea.

În acord cu tema pe care am supus-o analizei constatăm că elementele contractului de colonat au evoluat, s-au adaptat fiecărei epoci, de-a lungul timpului, astfel că, în zilele noastre, vorbim despre contractul de arendă.

Sistemul juridic românesc reglementează noțiunea de arendă, atât ca şi contract distinct dar şi ca varietate a contractului de închiriere, în care părțile contractante se află pe picior de egalitate juridică. Asemănarea dintre instituția colonatului și arenda din zilele noastre se raportează la epoci diferite şi la recunoaşterea unui statut diferit al persoanelor.

Două aspecte diferite între dreptul roman şi dreptul românesc ar fi de remarcat în legătură cu subiectul dezbatut, şi anume, prima ar fi aceea că dreptul roman nu asimila contractul de colonat cu contractul de închiriere/locațiune. Închirierea/locațiunea era considerată mai apropiată de contractul de vânzare (astfel cum reiese, printre altele, din Instituțiile lui Iustinian). ${ }^{14}$

O altă diferență importantă întâlnită la cele două contracte (colonatul şi arenda) o reprezintă subiectele raportului juridic ce stă la baza acestor convenții, şi anume: în perioada antichităţii romane vorbim despre proprietarii de pământuri/latifundiarii care își dădeau terenurile în folosință colonilor. Cu timpul colonii ajung dependenți de proprietatii terenurilor, fiind

\footnotetext{
14 Iustiniani Institutiones - Instituțiile lui Iustinian, Text latin și traducere în limba română, cu note și studiu introductiv de prof. dr. Doc. Vladimir Hanga, Editura Lumina Lex, București, 2002, pp.232-235.
} 
înstrăinați odată cu parcelele de teren pe care le lucrau. În perioada contemporană vorbim despre condiții de validitate ale contractului de arendă, ca act juridic civil bilateral, în care părțile se află pe picior de egalitate juridică și trebuie să își exprime liber consimțământul la încheierea actului respectiv.

Acest lucru demonstrează evoluția şi adaptarea normelor, odată cu schimbarea statutului juridic al persoanelor, cu recunoaşterea drepturilor şi obligațiilor corelative în parteneriatul contractual, inclusiv în materia arendei.

\section{Bibliografie}

Beard, Mary, SPQR. O istorie a Romei antice, Editura Trei, București, 2017 Ciucă, Valeriu M., Drept roman. Lecțiuni, ed. a II-a, addenda, corrigenda et incrementa, Editura Universităţii „Alexandru Ioan Cuza”, Iași, 2014

Gibbon, Edward, Istoria declinului şi a prăbuşirii Imperiului Roman, Editura Humanitas, București, 2018

Hanga, Vladimir, Iustiniani Institutiones - Instituțiile lui Iustinian, Editura Lumina Lex, București, 2002

Hanga, Vladimir; Bocşan, Mircea Dan, Curs de drept privat roman, ed. a IIa, Editura Universul Juridic, București, 2006

Hanga, Vladimir; Jakotă, Mihai, Drept privat roman, Editura Didactică și Pedagogică, București, 1964

Molcuţ, Emil; Oancea, Dan, Drept roman, Casa de editură şi presă „Şansa” SRL, Editura Universul, București, 1993

Sâmbrian, Teodor, Drept Roman. Principii, instituții și texte celebre, Casa de editură şi presă „Şansa” S.R.L., București, 1994. 